Rebecca Henn | Caldieron, Miller | Constance Bodurow Stallmeyer, Dearborn | Seth Wiley | Brian Szymanik

\section{The Next Generative Infrastructure for Detroit}

\author{
Constance Bodurow, Lawrence Technological University, \\ College of Architecture and Design
}

Detroit has a wealth of empty space, though little intelligence or understanding of it. There is a global, morbid fascination with Detroit's emptiness. The media and design disciplines have mythologized it in imagery, and obsessively mapped and quantified it. Vacancy perpetuates entrenched social, economic and environmental disparities and inequities (FIG 1). Yet, in the midst of formal 'right sizing' and informal urban agricultural initiatives, a constructive civic dialogue about the role of vacancy in the future of the city has yet to begin.

Our transdisciplinary design research lab wishes to prompt the dialogue. A new urban geography and ecosystem are required. Vacancy is a new infrastructure for the city. Vacancy, as it manifests, in land, buildings and infrastructure, is generative. We recommend productive, temporal uses for vacancy, to generate the next urban form of the city. In the same manner that grid and infrastructure become generators of urban form and use, vacancy can guide future urban form in Detroit.

We define infrastructure networks as the systemic and complex overlay required to support a city and its associated urbanized region. Connections occur largely through blue|green|gray+white infrastructure networks that span geographic, ecological and political boundaries. Vacancy emerges as the ubiquitous infrastructure in each of these typologies.

This paper describes aspects of our current project to create sustainable

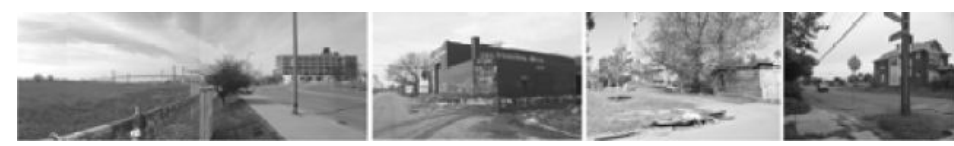

Figure 1

community and the central role which vacancy plays in achieving that goal. In one neighborhood of Detroit, we propose interventions for energy, density, and nature, envisioning an alternative, equitable, and sustainable ecosystem for the city.

\section{Introduction + Context}

This paper describes the approach, methodologies, and design applications developed by the author and studio[Ci] @ Lawrence Tech University. A new urban geography and ecosystem are required to balance the benefits and impacts of both shrinking and rapid urbanization. In response, we created the $\mathrm{Ci}$ methodology and GeoDesign interface to proactively design for the "coming together" of criteria into a spatial convergence. Our approach is transdiciplinary, integrative and collaborative. We combine urbanism, architecture, and engineering in a value/resource-based, community driven process. We utilize our interface to map data and conduct analysis, then develop urban design interventions based on indigenous capacities and abundant assets which can be geospatially mapped. Our current design application proposes Detroit's first Net Zero Energy Community in Southwest Detroit (SWD). 'We were funded by the Ford Motor Companyil to propose design interventions to propose sustainable urban form and systemically incorporate five elements of sustainable communities (hybrid alternative energy, urban mobility, density, public realm and green economy) into new "Energy/Density Hubs". As a result of this work, a relationship between infrastructure and vacancy in the city emerged, and prompted recommendations for generative uses for vacant land, focusing on hybrid renewable energy, target mixed use density, water cycle management and reforestation, in support of sustainable community and economic growth.

We work primarily in Detroit, Michigan USA, 16th largest city in the US iii, and located at the center of the Great Lakes Basin bioregion. Specifically, SWD, a 12,450 acre (5038.336 hectares) neighbourhood bordered by the CBD to the east, the Detroit River (and Canadian border) to the south and the Rouge River to the west (FIG. 2), which is growing, thriving and defying the generally negative media generated depiction.

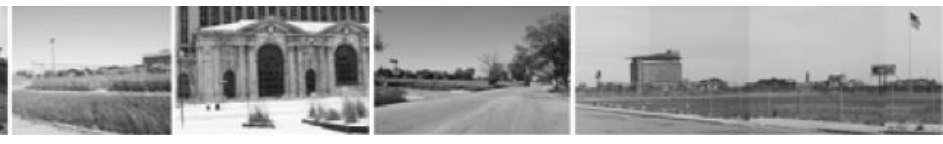

Currently facing state receivershipiv, the city has been and continues to be well documented in the national and international media. ${ }^{v}$ Despite the prevailing perception, SWD is a diverse and vibrant community, one of the only neighbourhoods in Detroit that is adding population, largely due to immigration, and serves as an ideal prototype for building a sustainable community. SWD has 106,749 residents in 41,694 households ${ }^{\mathrm{vi}}$.

SWD has extensive capacities and assets, identified in six categories (FIG 3). SWD contains the junction of major highway and rail infrastructure, and serves as a critical regional transportation hub. Two infrastructure projects, the Detroit Intermodal Freight Terminal (DIFT) and the New International 2 Trade Crossing (NITC) represent billions of investment from both the US and Canadian Federal governments. vii The 
neighbourhood has a base of high wage jobs and established employers. viii. Brownfields, and vacant buildings and parcels offer opportunities for generative use.

Cities are dynamic, existing in a state of continual change along a spectrum of urban growth--stasis and regression. In the last decade, the concept of urban shrinkage has been reinterpreted in concert
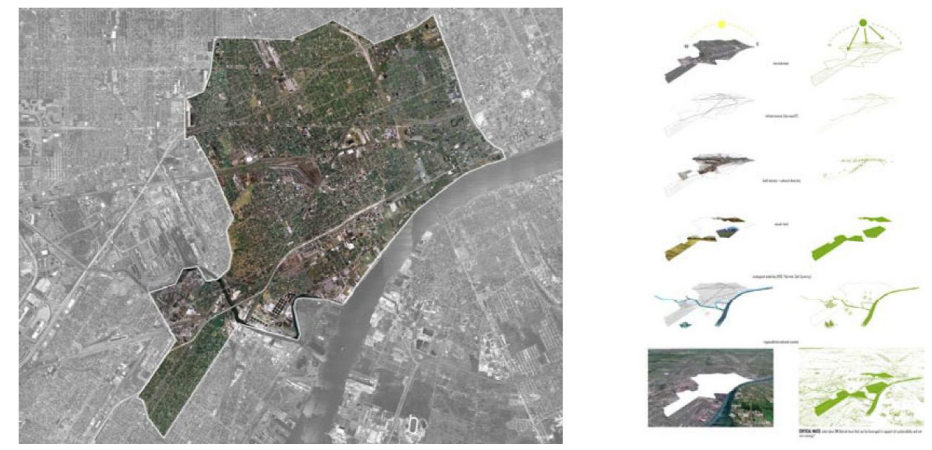

Figure 2, 3

with the reality of a globalized social, economic and environmental context, associated with the Post Industrial cityix. "Shrinking cities" have populations of 100,000 or more, with losses of over 10 percent in the last five decades ${ }^{x}$. The phenomenon was formalized by the German Federal Cultural Foundation's Shrinking Cities Projecti.

Detroit's regression has occurred over 50 years of slow attrition, and is the "poster child" of urban shrinkage. As such, an entire creative industry has emerged around a morbid fascination with Detroit. After the Stalking Detroit initiative at the outset of the 21st century ${ }^{x i}$, a flood of designers have studied the "blank slate" of Detroit's vast abandoned geography.

Within this context, the public, private and institutional sectors are acting to address Detroit's condition, with a particular emphasis on vacancy.

The city is spending millions in federal funding to demolition vacant homes with a goal of 10,000 structures over four years ${ }^{x i i i}$. A number of nonprofits are addressing the city's condition of vacancy, with a primary focus on residential structures and land. Community Legal Resources (CLR) delivers free legal services to nonprofit organizations building neighborhoods in Detroit. ${ }^{\text {xiv }}$ Since 1998, CLR has supported the Detroit
Vacant Property Campaign (VPC). VPC assists citizens and property owners and has developed a strategy which includes inventory and assessment of vacant homes. Data Driven Detroit (D3) was established in 2008 as an independent data center to promote positive community change by: "Building a community data warehouse of comprehensive, reliable, relevant information relating to social, economic and environmental indicators." ${ }^{\prime \prime v}$

In 2009, D3 mapped vacant land through the Detroit Residential Parcel Survey, with the Detroit Office of Foreclosure Prevention and Response (FPR), and CLR. xvi The survey revealed that more than 218,000 or 95 percent of single-family homes suitable for occupancy (FIG 5). The survey also found that 26 percent of the city's residential parcels - or

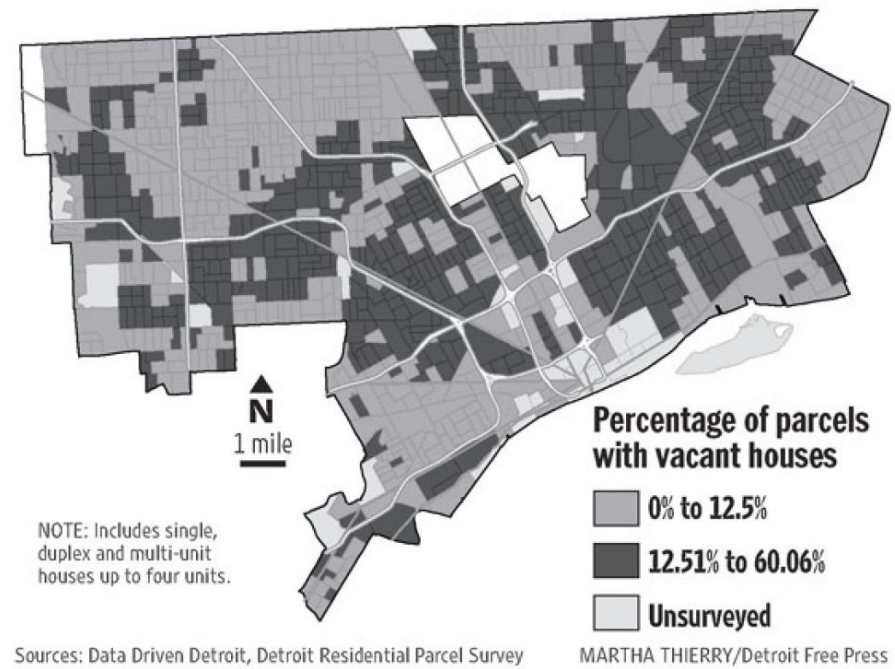

Figure 5

91,000 lots- were vacant. ${ }^{x v i i}$ (FIG 5).

To address disinvestment, vacancy, and other structural issues, the current Mayor initiated a "rightsizing" plan for the city, entitled the Detroit Works Projectxviii. Launched in 2010, the project is "a process to create a shared, achievable vision for our future that would serve as a guide for improving the physical, social and economic landscape of our city."xix

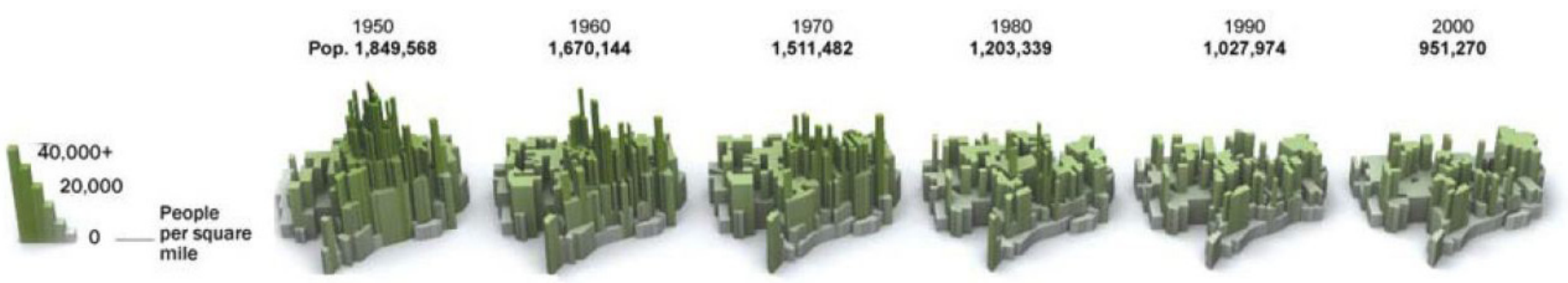

TIME Graphic by Andréa Ford and Lon Tweeten

Sources: U.S. Census Bureau, U.S. Postal Service, Department of Housing and Urban Development, Wayne State University Center for Urban Studies

Figure 4 
The Mayor announced some neighborhoods of Detroit would be abandoned and residents relocated. This prompted a series of contentious public meetings. ${ }^{x x}$ In response, the Mayor hired new consultants for two tracks-Short Term Actions for three Demonstration Areas $^{x \mathrm{x}}$ with the intention is "realigning some city services, and leveraging investments...to improve the market conditions..."; and Long Term Planning, which focuses on a "Strategic Framework Plan" outlining a series of recommendations to "Encourage innovative and productive ways to use land and improve the city's infrastructure."xxii Skeptical of the Administration's process and methodologies, the city's NGO community is pursuing parallel planning initiatives. ${ }^{\text {xxiii }}$

Productive use for vacancy has come from urban agricultural initiatives, led by the Greening of Detroit (TGD), with a mission to "guide and inspire the growth of a 'greener' Detroit through planting and educational programs...and by building community capacity." xxiv Zoning does not allow urban agriculture, but TGD collaborates with Planning to secure vacant lots. Since 2003, TGD's Garden Resource Program ${ }^{x \times v}$ supports over 1,300 gardens and farms and operates three urban farms and markets, provided farming resources and educational opportunities to over 15,000 urban gardeners. . Diverse initiatives exist related to vacancy in Detroit, several addressing land use, but few address design and long term intervention. A constructive civic dialogue about the role of vacancy in the future of the city has yet to begin. We wish to prompt that dialogue.

\section{Theory + Inspiration}

Many have addressed vacancy in the metropolis. Lerup could be speaking of Detroit, describing Houston's holey plane: "Here space in the European sense is scarce, perhaps nonexistent. With neither sea nor confining walls to define it, it consists only of a mottled plane to navigate...also crude and wild, marked by fissures, vacated space. Patently unloved yet naturalistic, this holey plane seems more a wilderness than the datum of a man-made city. "xxvi

Banham introduced the concept of the city as an ecological entity, identifying four typologies based on geography and infrastructure ${ }^{\text {xxvii }}$, Lerup's assertion that "the city must be seen as an organism... if not strictly or classically a city, then certainly an ecology..." "xxviii inspires our attitude.

Lerup creates the concept of "stim and dross": "precariously pinned in place by machines and human events these become the points of stimulation - stims" and Dross as - "the ignored, undervalued, unfortunate economic residues of the metropolitan machine."xxix

Detroit, with its dysfunctional real estate market and undervalued land, defies Lerup's analysis to an extent. But relevant is his discussion of an expanded notion of value, one which I have asserted in my theory of Value Densification $^{x x x}$. In Houston, speculative investment plays a stronger role in patterns of vacancy, but in Detroit, most vacant land is publicly owned. Further, Detroit's vacancy is highly associated with infrastructure networks, a legacy of the spatial logic of the automobile industry that shaped and dominated the city for so many decades. While vacancy is vast, public ownership and advantageous physical adjacencies make the condition more tractable for change.

Berger expands Lerup's concept of dross: "dross is understood as a natural component of every dynamically evolving city. As such it is an indicator of healthy urban growth. Drosscapes accumulate in the wake of the socio- and spatio-economic processes of deindustrialization, postFordism, and technological innovation" xxxi "...undervalued for many reasons (pollution, vacancy, natural conditions unsuitable for building, unprofitability, et al.)."xxxii This author would also add racism and the inherent inequities of the capitalist system.

We investigate the role that density plays in sustainable urbanism, but have proposed an alternative theoretical approach which is neither optimistic nor pessimisticxxxiii. - Convergence of Intensity [Ci] - xxxiv -meditates the two ends of the density spectrum. Our methodology presents an alternative, ethical approach. Ci proposes specific criteria for the "re-sizing" of the post-industrial city, arguing that balanced, sustainable, dense and urbane development is still possible. We call these limited intersections the new geography of the city. Decisions about future urban form in Detroit should be criteria (vs. data) driven, so the Ci methodology and GeoDesign interface enable the "coming together" of metrics [criteria] in three categories: Human [inhabitation]; Cultural [place], and Infrastructure [ecosystem], into a spatial convergence. ${ }^{\mathrm{xxv}}$

The fundamental question in "re-sizing" the city is: where and how will we sustainably redevelop [densify] and support resident populations with infrastructure, services and investment? Since answers to this essential question have been dominated by capricious political, market, and/ or social forces, the consistent description and application of metrics [criteria] are essential.

We accept current theoretical and design approaches of systemic design $^{x x x v i}$ and sustainable urbanism ${ }^{x x x v i i}$. No matter its growth profile, the city is a consumptive entity, challenging its ecological context, as Mostafavi observes. ${ }^{\text {xxviii }}$ For civilization to endure, cities must begin incorporate the natural systems that support their existence ${ }^{x x x i x}$. Within this systemic approach we define urban infrastructure broadly as blue|green|gray+white and view it as the new eco-system of the sustainable city, both reinforcing and defying social, political, and cultural boundaries in the same manner as natural systems.

\section{A new Urban Infrastructure Ecology}

Infrastructure networks are the systemic and complex over|underlay required to support a city and its associated region. Infrastructure is a key determinant of future urban form, and plays a significant role in establishing a more desirable and sustainable condition for urban growth and change. ${ }^{\mathrm{xl}}$ Infrastructure defines the natural and built ecosystem of the city. The convergence of multiple blue|green|gray+white infrastructure systems indicates the new geography of the city. 
Detroit is rich with technological infrastructure supporting manufacturing, movement of goods and services and associated human settlement. Defining "blue|green/gray+white": green infrastructure describes natural flora and fauna and related habitats, man-made landscape and greenway networks, precipitation collection, and criteria-rated buildings, sites and neighbourhoods; blue infrastructure describes the watersheds, floodplains, wetlands, and hydrology, gray infrastructure is entirely manmade, including highways, roads, rails, digital technology, and associated environmental impacts, and white is associated with telecommunications, energy generation and delivery. The resultant complex networks range in scale from the local and regional, to international.

Traditionally, urban infrastructure is defined as the grid. Martin proposed: "The grid of streets and plots... is like a net placed or thrown upon the ground" and: "the understanding of the way the scale and pattern of this ...net or grid affects the possible building arrangements on the land within it is fundamental to any reconsideration of the structure of existing towns." "xli

The grid as "net" is a vivid image: a flexible structure that can be mapped, lifted and deployed in more creative and generative ways. Detroit's extensive grid (and its associated and dense infrastructure of utilities that must be maintained by a bankrupt city) actually acts as an inhibitor of growth and change. The redundant grid associated with vacancy should be decommissioned and repurposed in support of new landscape ecologies.

The Smithsons add: "... roads (together with the main power lines and drains) form the essential physical infrastructure of a community... have the same power as any big topographical feature, such as a hill or a river, to create geographical, and in consequence, social divisions." xlii What if roads were not the only mode of mobility - or system for energy delivery, public lighting, water management systems - in the city?

What if infrastructure did not divide, but in a hybridized form, created spaces of connectedness? In Detroit, where the municipality cannot maintain roads and $1 / 3$ of adults do not own a car, the extensive network is obsolete. How can infrastructure serve necessary and sustainable functions and create geographical features without division? Other cities are pursuing this approach. ${ }^{\text {xliii }}$

Vacancy emerges as the ubiquitous infrastructure in each blue|green|gray+white typologies. Far from the interpretation of vacancy as a potentially or actually detrimental element of the city, we see vacancy as it manifests in land, buildings and infrastructure, as generative (capable of producing or creating) and of use in leveraging investment and other externalities. Vacancy provides an armature for collective dialogue, design intervention and policy. We recommend a variety of productive, temporal uses for vacancy, a generator of urban form and use, especially if hybridized with other infrastructures. As inherent and indigenous assets, vacant areas do not necessarily need to be rewoven into the urban grid and fabric in a traditional sense. Rather, they should take on new roles in their next iteration, though still connected and integral to existing and emergent spatial, social and natural systems.

We have created a Systemic Overlay of infrastructure to understand the profound connections and relationships between neighborhoods, city, and regional and international contexts. These environmental, social and economic connections occur largely through blue/green/gray+white infrastructure networks that span geographic, ecological and political boundaries.

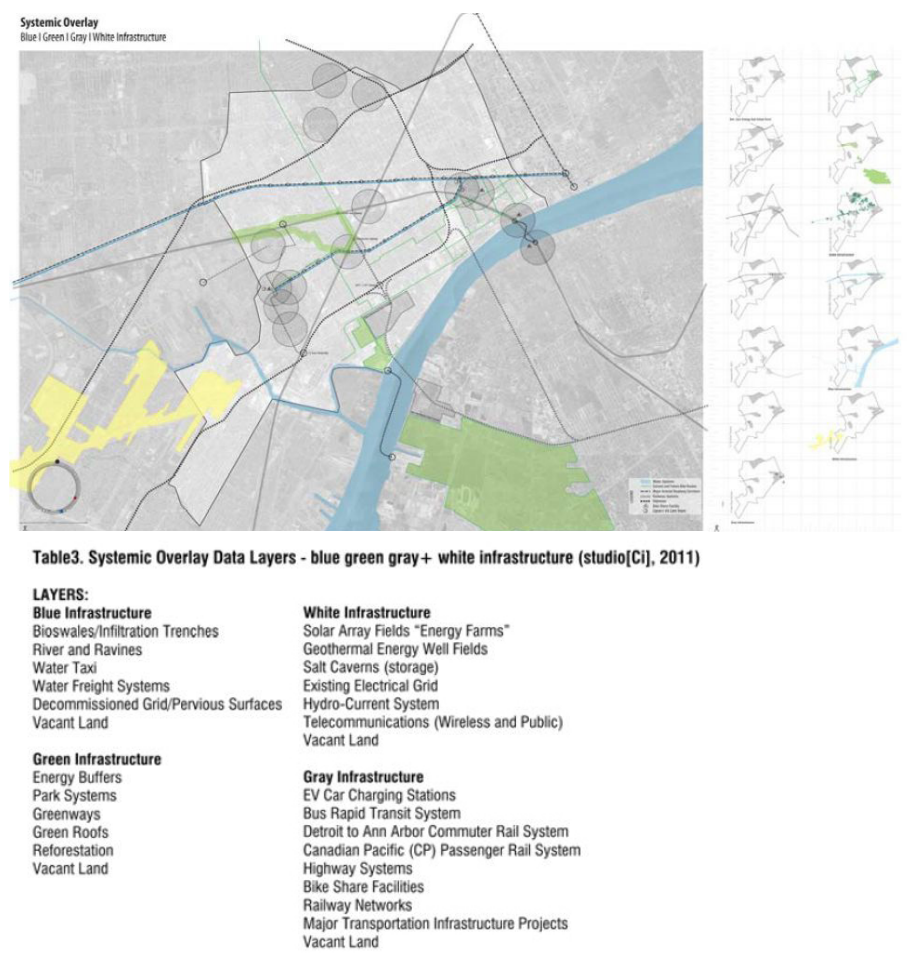

Figure 6,7

FIG 6 illustrates the compilation of multiple mapped data layers of infrastructure networks and systemic connectivity, representing the convergence of the multiple infrastructure systems that define the region and can be built upon to reinforce the net-zero energy vision. The Systemic Overlay also helps to define the 'geographic convergence' and locations of each of our proposed four Energy Hubs and Sub Hubs, along with their connective blue|green|gray+white infrastructure systems (FIG 7).

\section{Methodology + Application}

We are primarily humanists and urbanists, but influenced by geography and landscape methodologies, including Corner's "agency of landscape"xliv. Corner's threefold purpose: retrieval of cultural value; enhanced social program and utility; and restored ecological succession, has influenced our design approach to vacancy in Detroit. 
Emergent infrastructures should leverage local assets and indigenous capacities. Large swathes of SWD, including the Port of Detroit, the DIFT and the NITC, are certainly a "logistics landscape", as defined by Waldheim and Berger. Given this reality, we strive to integrate the cultural landscape, drawing them "together through shared spatial and material languages." ${ }^{\prime \prime V}$

A fundamental objective for our Ford C3 project has been re-purposing vacant land in SWD and its potential larger role in influencing the future of urban form in Detroit. GeoDesign interface analysis yielded 1,571 acres ( 635 hectares and $7611.4 \mathrm{~m}^{2}$ ) of vacant land. For design purposes, we categorized parcels into three categories: Vacant (V) $30 \%$; vacant w/abandoned structures (A) 30\%; and Vacant w/occupied structures

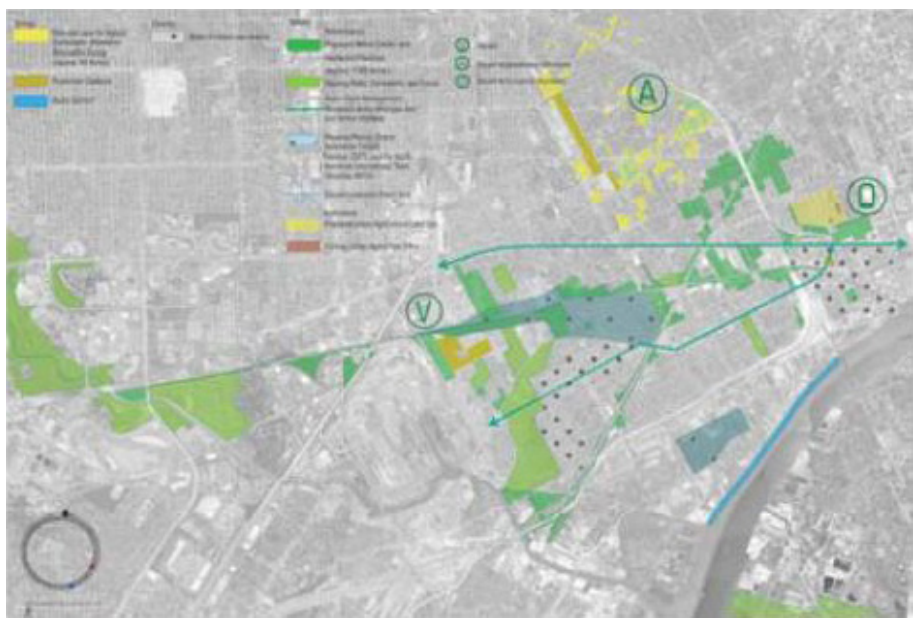

Figure 8

(0) $40 \%$ of parcels identified. FIG 8 illustrates the spatial dispersion of vacant parcels and the concentrations of vacancy in SWD: largely in the Condon and North Corktown neighbourhoods and arrayed along gray infrastructure corridors ${ }^{x v i}$. This presents an opportunity to identify, quantify and assemble vacant parcels and re-purpose them for generative use.

We recommend diverse new and reinforcing generative use for the repurposing of vacant land, including: 1 NATURE: reforestation, water

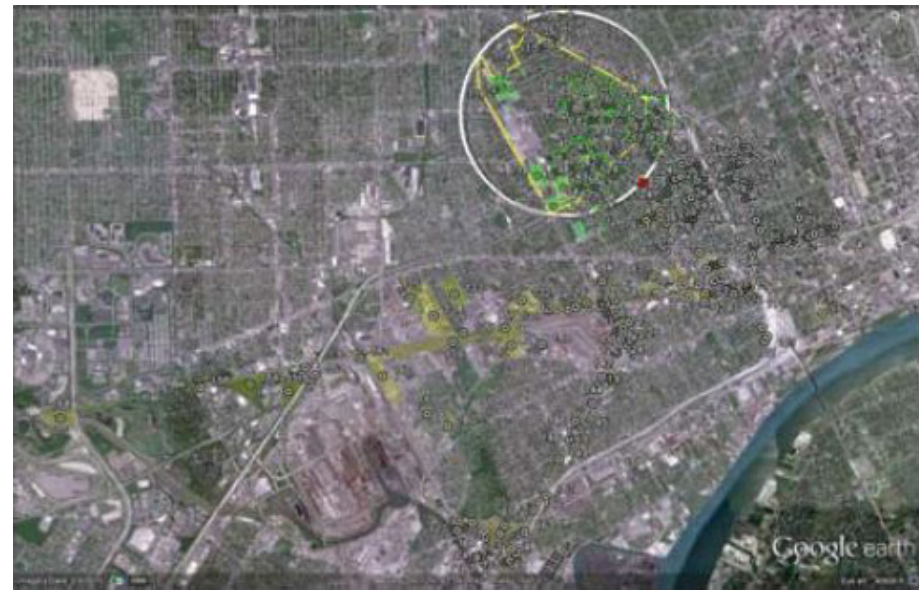

Figure 10

cycle management, and urban agriculture; 2 ENERGY hybrid alternative (renewable) energy, including solar, geothermal and hydro-current; and 3 DENSITY: areas for targeted density (both built and population). FIG 9 illustrates these proposed generative uses and how they array spatially in SWD; approximately 1,500 acres (635 hectares) of vacancy, in three categories. This new armature, in close proximity to infrastructure systems, supports our recommendations for generative uses for vacant and decommissioned land, buildings and infrastructure. We focus our $\mathrm{V}, \mathrm{A}, \mathrm{O}$ investigations (FIG 10) on Detroit's most iconic examples of vacancy (e.g. Michigan Central Station), those juxtaposed to economic stability providing opportunities to engage partners and remaining residents in joint ownership, training and management (e.g., Condon Neighborhood), and proposed regional/international infrastructure investment (e.g., DIFT). Each envisions an alternative, equitable, and sustainable ecosystem for the city.

As illustrated in FIG 11, we identified vacant parcels and proposed segments of adjoining decommissioned street grid while maintaining access for current and future land use. (FIG 11).

Design Interventions: nature, energy, density
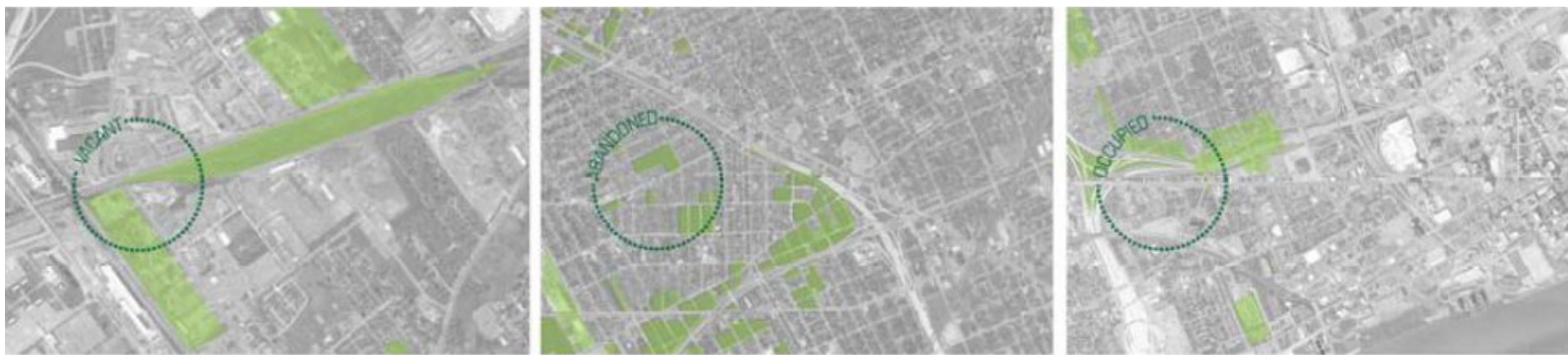

Figure 9 


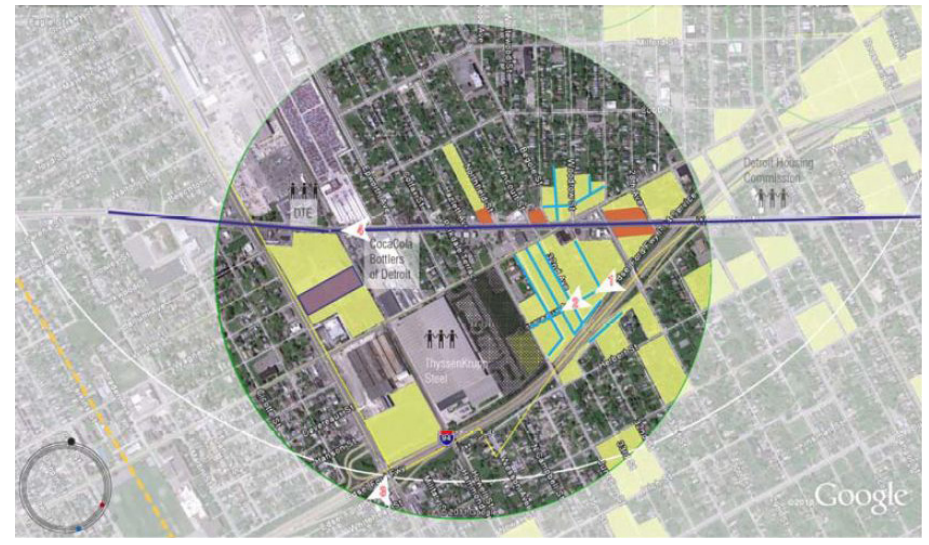

Figure 11

\section{NATURE: 1,100 Acres}

V: REFORESTATION at the DIFT (FIG 12).

We recommend that 1,100 acres of vacant land along rail lines in SWD in the vicinity of the proposed Detroit Intermodal Freight Terminal (DIFT) should become urban forest of deciduous trees (averaging 21 trees/ acre). Urban forests provide for SWD: Urban Heat Index Reduction - the shade cast on buildings can reduce energy usage during the warmer months, for a savings of $8,400,00 \mathrm{kWh}$ annually; Stormwater Run-off Mitigation - reforestation intercepts $90 \%$ of stormwater run-off, for , averting up to $227,187.18 \mathrm{ft}$ of runoff/year; Carbon Sequestration - trees sequester carbon from the environment through photosynthesis and store the by-product in the tree volume of bio-mass, which could mean sequestering up to 2.1 million tons of $\mathrm{CO} /$ year; Psychological + Economic (Social) Effects - studies have found the visual presence of forests have a positive effect on emotional wellbeing, and generate increased economic and community use.
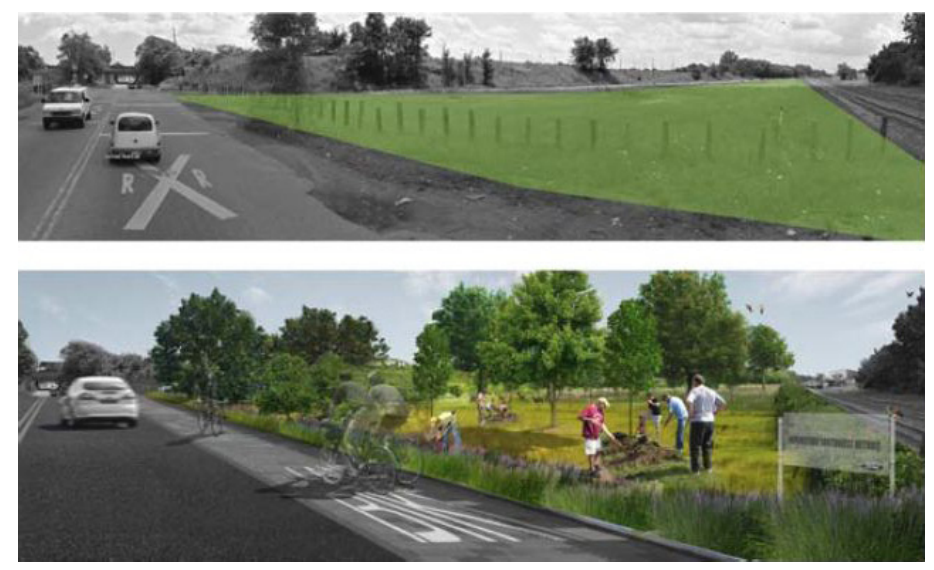

Figure 12

\section{ENERGY: 100 Acres}

A: ENERGY FARMS at ThyssenKrupp/Condon Neighbourhood (FIG 13). This neighbourhood selected for concentrations of vacant land, offers
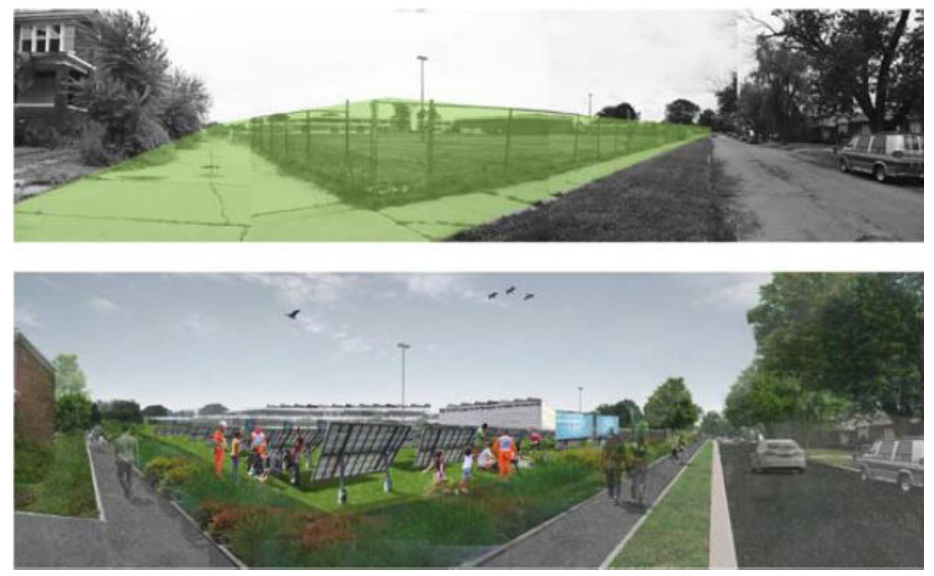

Figure 13

opportunities for the large scale generation of solar and geothermal energy, to decommission and repurpose redundant grid, and engage potential partners. We call these repurposed areas of SWD Energy Farms, utilizing vacant land and adjacent decommissioned street grid for the generation of alternative energy and - water management (rainwater collection and stormwater mitigation) through conversion to pervious surfaces and integration of bioswales. We recommend 100 acres of solar array installations and geothermal well fields - implemented on multiple acres to single lots - which could produce energy to meet neighbourhood electrical and mechanical demand. Partnerships with LTU, DPS, DTE, ThyssenKrupp Steel, and Coca Cola will create a new Education/ Research entity at the former Biddle School and the Sampson Weber Academy and "Outdoor Classroom" for the development, manufacture, installation, and maintenance of solar and geothermal technologies. A new management model would allow adjacent property owners and residents to be trained to play a role in the operation of the Energy Farms, affording remaining citizens in depopulating areas the opportunity to have a generative role in the community.

\section{DENSITY: 10 ACRES}

$\mathrm{O}$ : at the Convergence of Infrastructure (FIG 14).

We have identified approximately 10 acres to catalyse intermodal oriented development in the vicinity of Michigan Central Station [MCS]. Infrastructure to support projected new built density and population includes: a proposed passenger rail stop at MCS, a proposed BRT stop on Michigan Avenue, a Detroit DOT bus stop on Vernor, and new onsite electric vehicle designated parking spots, public parking, and bike racks. A new pedestrian bridge would span across our proposed MCS International GreenLink and the rail corridor connecting the Mexicantown and Corktown neighbourhoods. The area contains occupied structures and emergent uses related to Roosevelt Park and MCS.

MCS [solar]: since its opening in 1913, MCS has served as a hub of activity for Regional Detroit. MCS is iconic -- both in its form and its 

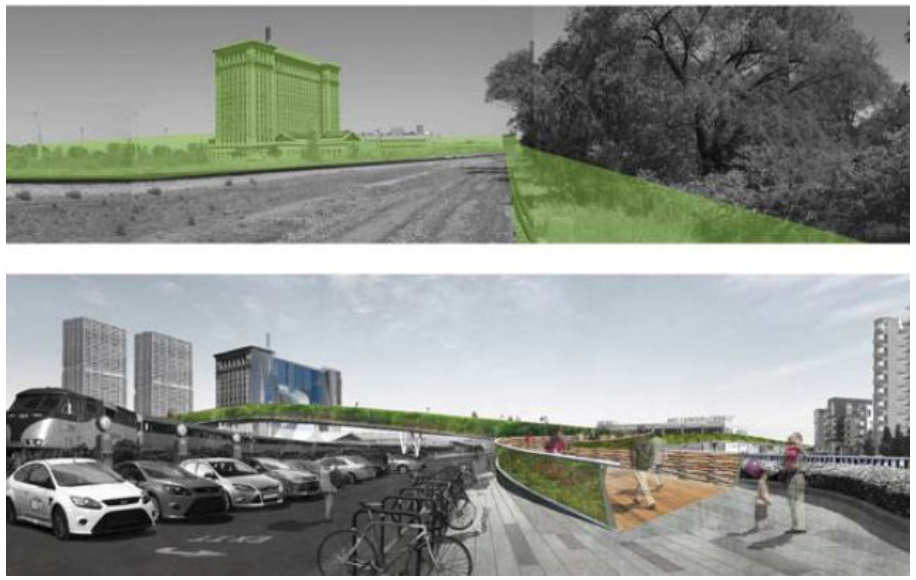

Figure 14

abandonment and transformative: from travesty to icon of the city's future - one of hope, vision and sustainability. Through extensive Ecotect modelling and use of a Markvart table for calculating optimal solar energy, we determined that MCS [solar]'s south, east and west facades and roof are ideally oriented to maximize solar collection with a photovoltaic array that would not preclude adaptive reuse of the historic structure (FIG 15). Based on our analysis, MCS [solar] could generate substantial alternative energy to support future adaptive reuse and for the surrounding neighbourhood.

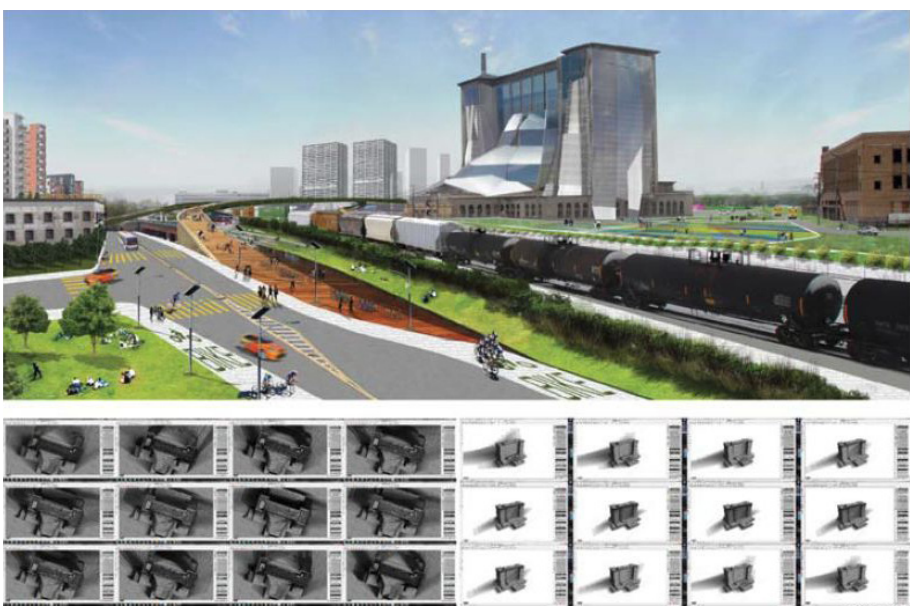

Figure 15

\section{Conclusion}

Vacancy can become a generative infrastructure - generative of emergent spatial, social, and natural systems - when hybridized with adjacent blue|green|gray+white infrastructure. As illustrated with our initial design interventions, vacancy in land, grid and buildings can create a new geography which speaks to the future form of the city. We employed our methodology and interface to support the creation of both formal and policy recommendations to encourage decision making around balancing the long term benefits and impacts of rethinking this hybridization of natural systems, infrastructure, and an expanded notion of urban density. While Detroit serves as the context for our first design interventions, we believe that our design methodology is scalable and replicable to prompt dialogue and envision an alternative, equitable, and sustainable ecosystem for urbanized regions across the globe.

\section{Bibliography}

Berger A D Drosscape. New York, Princeton Architectural Press, New York, 2006.

Berger, A Systemic Design can Change the World, SUN architecture.nl [English edition], 2009.

Banham, R. Los Angeles: The Architecture of Four Ecologies, University of California Press, Berkeley and LA, 2001.

Bodurow C C D IND DEV: Industrial spatial logic and the transformation of the city. In Proceedings of the ACSA Central Regional Conference, University of Wisconsin-Milwaukee School of Architecture and Planning, Milwaukee, Wisconsin, 2006.

Bodurow C C City of Worth: Value Densification Community Pilot Project (VDCpp). In Proceedings of the ACSA Annual Meeting, University of Houston School of Architecture, Houston, Texas, 2008.

Bodurow C C Research Partner, Research Partner and Research Assistant Multivariable Value Densification Modeling Using GIS. Transactions in GIS, 13(s1) Blackwell Publishing Ltd., 2009.

Bodurow C C We are (or aren't) alone Second thoughts on Shrinking Cities. Detroit, Metro Times, 2007.

Brown, $\mathrm{H}$, Infrastructural Ecologies: Principles for Post-Industrial Public Works, The Design Observer Group, 2010.

Corner, J. Ed. Recovering Landscape, Princeton Architectural Press, 1999. Koolhaas R Delirious New York: A Retroactive Manifesto for Manhattan. New York, Oxford University Press, 1978.

Lerup, L STIM \& DROSS: Rethinking the Metropolis, Assemblage 25, MIT Press, Cambridge, MA, 1995.

Lerup, L After the City, MIT Press, Cambridge, MA, 2000.

Maas W (ed) MVRDV: KM3 Excursions on Capacity. Barcelona, Actar, 2006.

Martin, L Grid as Generator, Urban Space and Structure, Cambridge University Press, 1972.

McHarg I L Design with Nature. Garden City, NY Natural History Press, 1969.

Mostafavi, M. with Doherty, G. Editors: Ecological Urbanism, Harvard University Graduate School of Design, Lars Müller Publisher, 2010.

Oswalt P Shrinking Cities. www.shrinkingcities.com

Perloff H S Planning The Post-Industrial City. Chicago Planners Press, 1980.

Sassen S The Global City: New York, London, Tokyo. Princeton and Oxford, Princeton University Press, 1991.

Shaw D V 2001 The Post Industrial City Handbook of Urban Studies London Sage Publications Ltd 
Smithson, A. (ed), Team 10 Primer, MIT Press, Cambridge, MA, 1968. Varnelis, K, Ed., The Infrastructural City: Networked Ecologies in Los Angeles, Barcelona New York, Actar, 2009.

Waldheim C and Berger, A, Logistics Landscape, Waldheim and Berger, Landscape Journal, 2008, 27:2-08, 2008.

Waldheim C (ed) The Landscape Urbanism Reader. New York, Princeton Architectural Press, 2006.

Waldheim C, Daskalakis C, Young J (eds) Stalking Detroit. Barcelona, ACTAR, 2001

Wolf-Powers, L, Is New Orleans a Shrinking City? Places, Vol. 19 Issue $1,2007$.

\section{ENDNOTES}

i From the U.S. National Renewable Energy Lab (NREL): "A net zeroenergy community (ZEC) is one that has greatly reduced energy needs through efficiency gains such that the balance of energy for vehicles, thermal, and electrical energy within the community is met by renewable energy."

ii The Ford Motor Company Fund's Community College Challenge (Ford c3).

iii US Census, 2010

iv http://www.nytimes.com/2012/03/08/us/mayor-of-ailing-detroit-resistsoutsidetakeover. html?_r=1\&ref=monicadavey

v Carr D 2009 Investment in a City of Struggles. New York, The New York Times

vi US Census, 2010

vii http://www.michigan.gov/mdot/

viii Ford Rouge Plant, Severstal Steel, National Steel, the Port of Detroit, ThyssenKrupp Steel, Detroit Thermal Energy (DTE), et al.

ix Perloff, 1980

$x$ Wolf-Powers, 2007, p.87

xi Oswalt, 2004. The project featured four cities - Detroit, Ivanovo, Manchester, Liverpool and Halle, Leipzig. See: www.shrinkingcities.com; xii Daskalaskis, G., Waldheim, C., \& Young, J. (2001)

xiii HUD funding from the Neighbourhood Stabilization Act. By policy, NSA funds cannot be used for revitalization, only demolition.

xiv http://clronline.org/about

xv http://datadrivendetroit.org/

xvii The VPC and D3 have recently mapped updated data of Detroit's vacant parcels, but have not been made data publicly available. http:/l datadrivendetroit.org/projects/detroit-residential-parcelsurvey/

xviii Happold Consulting for the City of Detroit, The Detroit Works Project; Phase One: Research and Priorities Policy Audit Topics, in progress V2December 22, 2010. See also: Restarting The Motor City: Bing, Detroit begin crafting city's future with community meetings, by Steve Neavling, Detroit Free Press, September 15, 2010

xix http://detroitworksproject.com/

xx See: http://www.mlive.com/news/detroit/index.ssf/2010/09/detroit_ works_project_bing_see.html xxi Criteria for selection of the demonstration areas were never made public. One is in our study area: Hubbard Farms/Southwest. See: http:// www.detroitmi.gov/DepartmentsandAgencies/MayorsOffice/Initiatives/ ShortTermActionsfortheDetroitWorksProject/DemonstrationAreas.aspx xxii lbid

xxiii CDAD's Neighbourhood Revitalization Strategic Framework which identifies nine neighbourhood typologies. See: http://cdad-online.org/ resources/strategic-framework/; and http://www.crainsdetroit.com/ article/20110731/FREE/307319973/questions-dog-detroit-worksplanadvocates-want-to-see-long-term-strategy\#

xxiv http://detroitagriculture.net/

xxv The founding partners of the Garden Resource Program Collaborative are TGD, EarthWorks Urban Farm, Michigan State University Extension, and the Detroit Agriculture Network.

xxvi Lerup 1995, p. 87

xxvii Banham, 1971, p19, 77, 143, 195.

xxviii Lerup 1995, pgs. 88-89

xxix Lerup, p.93

xxx Bodurow, 2006, 2008, 2009

xxxi Berger, 2006, p. 36

xxxiii See Bodurow (2010) for discussion of "Unlimited Vacuum" and Unlimited Capacity" relating to urban density.

xxxiv Building on the author's theory of Value Densification:" a focus on investment and density in neighbourhoods and districts were social, cultural and infrastructural value and densities are in evidence", first published in 2006.

xxxv Bodurow, C, et al. 2009

xxxvi Berger, A 2009, p.13-14

xxxvii Joachim, Mitchell, "Envisioning Ecological Cities" (2010), p. 224229

xxxviii Mostafavi, Mohsen, 2010, p. 17

xxxix Specifically, the Cities as Sustainable Ecosystems [CASE] method, based on the Melbourne principles, described in Newman and Jennings(2008)

xl Varnelis, 2009, et al.

xli Martin, 1972, p.10

xlii Smithson, 1968, p. 51

xliii Applebaum, A., New York's Green Grid, April 17, 2011, The New York Times Sunday Opinion, p. 9.

xliv Corner, 1999, p. 4

xlv Waldheim and Berger, 2008, p. 243

xlvi US Census, 2010. 